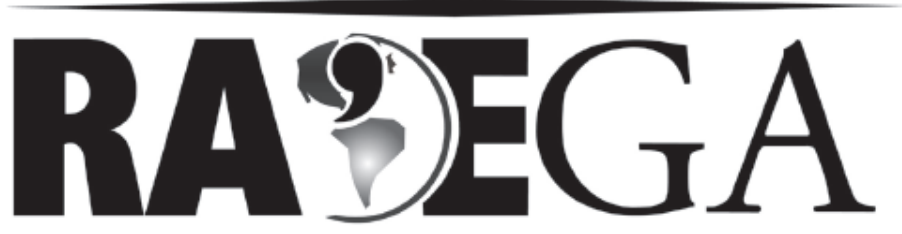

O ESPAÇO GEOGRÁFICO EM ANÁLISE

\title{
IMPACTOS SOCIAIS DA MINERAÇÃO DO FOLHELHO PIROBETUMINOSO SOBRE A COMUNIDADE RURAL DOIS IRMÃOS, DESAPROPRIADA PARA FINS DE UTILIDADE PÚBLICA
}

\section{SOCIAL IMPACT MINING OF OIL SHALES OVER THE RURAL COMMUNITY DOIS IRMÃOS EXPROPRIATED FOR PUBLIC UTILITY}

\author{
Carmen Ballão WATANABE ${ }^{1}$ \\ Gilda Carneiro FERREIRA ${ }^{2}$
}

\section{RESUMO}

O objetivo desse artigo é apresentar os efeitos dos impactos sociais da mineração do folhelho pirobetuminoso sobre a comunidade rural Dois Irmãos, localizada no município paranaense de São Mateus do Sul. Para minerar, a PETROBRAS/SIX precisa desapropriar áreas de seu interesse. Para a implantação da última mina aberta em 2010 - Mina Dois Irmãos - foram desapropriadas terras de 90 famílias, que sofreram diretamente os impactos da mineração. Destas, 62 famílias foram entrevistadas com a finalidade de se

\footnotetext{
${ }^{1}$ Graduada em Geografia pela Faculdade Estadual de Filosofia, Ciências e Letras de União da Vitória (1993). Especialização em Análise Ambiental pela Universidade Federal do Paraná (1999). Mestre em Geografia pela Universidade Federal do Paraná (2002). Doutora em Geociências e Meio Ambiente pela Universidade Estadual Paulista Júlio de Mesquita Filho (2010). Professora do Instituto Federal de Educação, Ciência e Tecnologia do Paraná.

E-mail <carmen.ballao@ifpr.edu.br>

${ }^{2}$ Graduada em Engenharia de Minas pela Universidade Federal de Ouro Preto (1981), Mestre em Engenharia Mineral pela Universidade de São Paulo (1989) e Doutora em Geociências e Meio Ambiente pela Universidade Estadual Paulista Júlio de Mesquita Filho (1995). Professora da Universidade Estadual Paulista Júlio de Mesquita Filho.

E-mail <gildacf@rc.unesp.br>
} 
investigar os principais efeitos sofridos com a desapropriação. Os resultados desta pesquisa evidenciaram que a comunidade desapropriada teve dificuldades na readaptação do modo de vida em novos lugares, sofrendo como os diferentes tipos de problemas desencadeados a partir da perda de suas terras.

Palavras-chave: impactos sociais; mineração; folhelho pirobetuminoso; desapropriação.

\section{ABSTRACT}

The aim of this paper is to present the effects of social impacts of Petrobras/Six mining of oil shales over the rural community Dois Irmãos, located at Sao Mateus do Sul city, Paraná state. For making mining areas, PETROBRAS/SIX needs to expropriate areas of its interest. In 2010, for the implementation of the mine Dois Irmão, the last one, 90 families were evicted and they directly suffered the impacts of mining. Of these, 62 families were interviewed in order to investigate the main effects suffered with the expropriation. These results showed that the community had difficulties in upgrading its way of life in new places, experiencing how different types of problems were triggered from the loss of the lands.

Keywords: social impacts; mining; oil shales; expropriation.

\section{INTRODUÇÃO}

A busca em apreender os efeitos dos impactos ambientais da mineração sobre a sociedade conduziu a delimitação do tema deste artigo, resultante de uma pesquisa bibliográfica e de campo que teve como objeto de estudo a mineração do folhelho pirobetuminoso em São Mateus do Sul, Paraná, Brasil.

A área de estudo localiza-se no município paranaense de São Mateus do Sul, que está situado entre os paralelos $25^{\circ} 44^{\prime}$ 'S e $26^{\circ} 08^{\prime} \mathrm{S}$ e os meridianos $50^{\circ} 09^{\prime} \mathrm{W}$ e $50^{\circ} 39^{\prime} \mathrm{W}$, possuindo uma área total de $1.334,522 \mathrm{~km}^{2}$, dos quais 7 $\mathrm{km}^{2}$ pertencem à PETROBRAS/SIX. A área utilizada pela empresa abrange terras urbanas e rurais, ocorrendo sobre essas últimas o avanço da lavra a céu aberto do folhelho pirobetuminoso.

O folhelho pirobetuminoso é uma rocha sedimentar da qual é possível 
extrair óleo combustível (betume) alternativo ao petróleo. As reservas brasileiras são de aproximadamente 800 bilhões de barris in place, distribuídas entre oito formações geológicas, das quais a Formação Irati, pertencente à seqüência gondwânica da Bacia Sedimentar do Paraná, é a mais importante pela capacidade de produzir "1,1 bilhão de barris de óleo, 73,8 bilhões de metros cúbicos de gás combustível, 4,5 milhões de toneladas de gás liquefeito e 48 milhões de toneladas de enxofre". (MINEROPAR, 2010).

Para extrair óleo combustível do folhelho pirobetuminoso, a PETROBRAS-SIX lavra a jazida a céu aberto e, posteriormente, processa o minério, utilizando-se de tecnologia própria, representada pelo processo Petrosix. (REVISTA DA PETROBRAS, 2001). Estas atividades de mineração provocam alterações nos aspectos físicos, químicos, biológicos e sociais do sistema ambiental local, gerando impactos de diferentes ordens, significâncias e magnitudes, o que pode desencadear conflitos sócio-ambientais entre a empresa e a comunidade diretamente afetada pela desapropriação de suas terras, necessária ao avanço da frente de lavra.

A aquisição das propriedades pela empresa é assegurada por decreto federal expropriatório, que a considera uma desapropriação para fins de utilidade pública.

O Decreto Federal de 24 de agosto de 2000 autorizou a PETROBRAS/SIX a desapropriar 15.395.025 $\mathrm{m}^{2}$ de área de seu interesse, abrangendo partes de duas comunidades rurais de São Mateus do Sul: Rio das Pedras e Dois Irmãos. (DECRETO, 2010).

O processo de negociação das propriedades, conduzido pela PETROBRAS/SIX e acompanhado pelo Ministério Público, pelo Instituto Ambiental do Paraná e por representantes das comunidades envolvidas, foi realizado em duas etapas que ocorreram, respectivamente, em 2001 e 2005. (PETROBRAS, 2006).

$\mathrm{Na}$ primeira etapa foi desapropriada uma área de 387,2 hectares, pertencentes a 70 famílias da Comunidade Rio das Pedras e, na segunda, 646 hectares de terras pertencentes a 90 famílias da Comunidade Dois Irmãos. Esta não foi a primeira e, provavelmente, não será a última desapropriação 
realizada pela PETROBRAS/SIX para expandir sua área de lavra, gerando insatisfação das pessoas que deslocam-se involuntariamente de suas propriedades. Após a desapropriação, algumas famílias permaneceram em sua comunidade de origem, vivendo em áreas próximas das antigas propriedades, e outras migraram para o meio urbano, abandonando a atividade agrícola praticada há décadas.

O impacto da desapropriação, causado pela aquisição de terras pela PETROBRAS/SIX, vem provocando efeitos a longo prazo no modo de vida dessas famílias e no meio ambiente como um todo. Redes de relações sociais e culturais foram desestruturadas devido ao deslocamento humano involuntário, ao mesmo tempo em que novas fronteiras agrícolas foram abertas, desencadeando outros impactos ao meio ambiente.

\section{METODOLOGIA DA PESQUISA}

\subsection{PÚBLICO ALVO}

O público alvo da presente pesquisa é composto por 90 famílias da Comunidade Dois Irmãos, que tiveram suas terras desapropriadas pela PETROBRAS-SIX, em 2005. São, em sua maioria, descendentes de poloneses, que se dedicam à agricultura, destacando-se o cultivo de milho e da soja, e ao extrativismo da erva-mate. As características mais marcantes da comunidade são o conservadorismo das tradições culturais e religiosas e a ajuda mútua de famílias vizinhas no desenvolvimento de atividades agrícolas.

\subsection{INSTRUMENTO DE PESQUISA}

O questionário foi o instrumento de pesquisa utilizado na coleta dos dados sobre os efeitos de longo prazo dos impactos da mineração sobre a Comunidade Dois Irmãos. Estruturado com 28 questões, sendo 24 fechadas e 4 abertas, o questionário teve a finalidade de conduzir a interpretação dos dados de forma objetiva, evitando distorções na análise das informações. 
As perguntas elaboradas foram distribuídas em três principais assuntos, para identificar o conhecimento da comunidade Dois Irmãos sobre: as atividades desenvolvidas pela PETROBRAS/SIX; o meio ambiente; e, os efeitos dos impactos ambientais da implantação e operação da Mina Dois Irmãos.

O conhecimento sobre as atividades de mineração da PETROBRAS/SIX e o sobre o meio ambiente foram consideradas importantes variáveis na identificação dos efeitos dos impactos ambientais sobre a Comunidade Dois Irmãos, a partir das respostas apresentadas pelos informantes no preenchimento dos questionários.

Com a finalidade de facilitar a compreensão dos entrevistados durante a elaboração das perguntas, a nomenclatura geológica do folhelho pirobetuminoso foi substituída por "xisto", termo de uso comum em referência ao minério, embora incorreta do ponto de vista das ciências geológicas.

\subsection{DEFINIÇÃO DAS QUESTÕES RELEVANTES DO ESTUDO}

Segundo Sánchez (2008, p 159), um estudo sobre impactos ambientais não pode prescindir de um planejamento que inclua a determinação daquilo que é relevante."

Para identificar as questões mais relevantes a serem consideradas no levantamento dos impactos ambientais resultantes da implantação e operação da Mina Dois Irmãos, foram seguidas as diretrizes apresentadas por Sánchez (2008, p.147), que afirma que "pelo menos três critérios têm se mostrado úteis para definir as questões relevantes em um estudo de impacto ambiental: experiência profissional dos analistas; opinião do público; requisitos legais."

Os requisitos legais se mostram os mais expressivos, por serem reconhecidamente obrigatórios, embora tenham sido estabelecidos democraticamente. Portanto, recorreu-se à análise da legislação ambiental pertinente ao presente estudo, consultando-se a Constituição Federal, o Código de Mineração, o Regulamento do Código de Mineração, Lei ㄲo․ 
6938/81, Decreto Expropriatório de 24/08/04, Portaria DNPM 40/00, Resoluções Conama 001/86, 09/87, 09/90 entre outras.

A opinião do público foi coletada por meio da aplicação de questionário. Os pontos principais levantados foram o conhecimento sobre as atividades de mineração desempenhadas pela PETROBRAS/SIX, o entendimento sobre o meio ambiente, e os efeitos dos impactos ambientais da mineração sobre as relações sociais, culturais e econômicas.

$\mathrm{Na}$ presente pesquisa a experiência profissional dos analistas citada por Sáchez (2008), foi considerada a experiência acadêmica da pesquisadora por se tratar de uma pesquisa científica sobre impactos ambientais, e não de um estudo de impacto ambiental propriamente dito. Foram analisadas diversas teses e dissertações que apresentaram a mineração do folhelho pirobetuminoso como tema central das discussões. Poucas abordaram especificamente os impactos ambientais decorrentes da atividade de mineração desenvolvida pela PETROBRAS/SIX, sendo o processo de industrialização do minério o maior enfoque da maioria delas. Assim, a análise dos impactos ambientais apresentados no Estudo de Impactos Ambientais (EIA) da Mina Dois Irmãos se mostrou de grande valia para complementar a pesquisa bibliográfica. Foram analisados os impactos provocados nos meios físico, biótico e antrópico descritos no EIA, identificando-se a significância atribuída a cada um deles.

Os dados coletados durante a pesquisa bibliográfica foram considerados a base teórica para fundamentar a pesquisa de campo. Foram realizadas duas visitas técnicas na área minerada pela PETROBRAS/SIX, em momentos distintos da realização da pesquisa, sendo possível visualizar todas as etapas da mineração e os respectivos impactos ambientais de cada atividade desenvolvida durante o processo de implantação e operação de uma mina de extração do folhelho pirobetuminoso.

A partir dos três critérios anteriormente descritos, foi possível levantar os principais impactos ambientais resultantes das atividades de mineração da PETROBRAS/SIX. Primeiramente foram listadas as principais atividades da mineração identificadas na pesquisa de campo, seguindo o modelo de lista 
proposto por Sánchez (2008, p. 182). Considerando os requisitos legais, a opinião pública e a pesquisa realizada, os impactos ambientais levantados foram relacionados com cada atividade desenvolvida nas fases de implantação e operação da Mina Dois Irmãos.

De acordo com os critérios adotados para o levantamento dos impactos ambientais, três destes se mostraram mais significativos do ponto de vista investigativo, a saber: a desapropriação de terras (opinião do público alvo); rebaixamento do nível freático e contaminação das águas subterrâneas (requisitos legais); e, ruídos e vibrações (experiência da pesquisadora e opinião do público alvo). Desta maneira, optou-se por um recorte quantitativo, selecionando-se apenas um desses três impactos, para ser analisado detalhadamente: a desapropriação de terras.

Considerando que a opinião pública tem grande peso no direcionamento de políticas públicas ambientais e, principalmente, na elaboração de normas do ordenamento jurídico de um país democrático como o Brasil, a presente pesquisa investigou detalhadamente o impacto da desapropriação de 646 ha de áreas pertencentes a 90 famílias da Comunidade Dois Irmãos, realizada pela PETROBRAS/SIX, em 2005, conforme apresentado neste artigo.

\section{A DESAPROPRIAÇAO DE TERRAS PARA FINS DE UTILIDADE PÚBLICA}

Anualmente, cerca de 6 milhões de pessoas são desapropriadas para a implantação de projetos de estradas de rodagem, eletricidade, mineração, entre outros, deslocando-se involuntariamente de suas terras. (CERNEA, Banco Mundial, 1994 apud SÁNCHEZ, 2008, p. 350).

De acordo com Di Pietro (2006, p. 134), a desapropriação é "o procedimento administrativo pelo qual o Poder Público ou seus delegados, mediante prévia declaração de necessidade pública, utilidade pública ou interesse social, impõe ao proprietário a perda de um bem, substituindo-o em seu patrimônio por justa indenização."

Para Bandeira de Mello (1997, p. 523), a desapropriação se trata de um: 


\begin{abstract}
procedimento através do qual o Poder Público, fundado em necessidade pública, utilidade pública ou interesse social , compulsoriamente despoja alguém de um bem certo, adquirindo-o originariamente mediante indenização prévia, justa e pagável em dinheiro, salvo no caso de certos imóveis urbanos ou rurais, em que, por estarem em desacordo com a função social legalmente caracterizada para eles, a indenização far-se-á em títulos da dívida pública, resgatáveis em parcelas anuais e sucessivas, preservado seu valor real.
\end{abstract}

As duas definições apresentadas anteriormente evidenciam que 0 Estado é detentor do poder de desapropriar os imóveis considerados de utilidade pública e, por eles, pagar indenização justa, conforme estabelece a Constituição Federal.

De acordo com o artigo 5ำ, inciso XXIV da Constituição Federal, "a lei estabelecerá o procedimento para desapropriação por necessidade ou utilidade pública, ou por interesse social, mediante justa e prévia indenização em dinheiro, ressalvados os casos previstos nesta Constituição." (BRASIL, 2004, p. 21)

Um bem é declarado de utilidade pública quando o Poder Público manifesta sua intenção de adquiri-lo, submetendo-o à expropriação. (MEIRELLES, 1995, p. 525). Este conceito se aplica aos casos relacionados à exploração dos recursos minerais, visto que estes são considerados bem da União conforme expressa o artigo 20 da Constituição Federal. (BRASIL, 2004, p. 48).

A separação do direito da propriedade do direito de exploração do subsolo já estava prevista na Constituição de 1934, assim como no Código de Mineração, pelo Decreto 24.642/34. Neste caso, o subsolo deve ser entendido como as camadas geológicas constituídas de recursos minerais com utilidade econômica, superficiais ou não. (MEIRELLES, 1995).

Embora não caiba ao desapropriado discutir seu direito sobre o subsolo, a ele cabe uma indenização justa, que cubra o valor real de todas as suas terras e as benfeitorias sobre elas instaladas.

De acordo com Meirelles (1995, p. 525) a indenização é justa quando:

cobre não só o valor real e atual dos bens expropriados, à data do pagamento, como, também os danos emergentes e os lucros 
cessantes do proprietário, decorrentes do despojamento do seu patrimônio. Se o bem produzia renda, essa renda há de ser computada no preço, porque não será justa a indenização que deixe qualquer desfalque na economia do expropriado. Tudo que compunha seu patrimônio e integrava sua receita há de ser reposto em pecúnia no momento da indenização; se o não for, admite pedido posterior, por ação direta, para complementar-se a justa indenização.

Portanto, Meirelles (1995, p. 525) defende a idéia que para ser considerada justa a indenização deve incluir "o valor do bem, suas rendas, danos emergentes, os lucros cessantes, além dos juros compensatórios e moratórios, despesas judiciais, honorários de advogado e correção monetária."

A indenização em dinheiro é uma maneira de compensar os efeitos da desapropriação, porém é possível mitigar ainda mais esses efeitos por meio da implantação de projetos de reassentamento, nos quais seja possível reproduzir as mesmas condições de vida.

Sánchez (2008, p. 351) destaca que no passado quando se recorria à desapropriação para fins de utilidade pública "o deslocamento das pessoas era tratado com descaso". As indenizações eram pagas, contudo, havia negligência na mitigação dos impactos sociais daqueles que sofriam todo 0 processo de desapropriação, assim como no tratamento dos impactos negativos que afetavam os ecossistemas. Este tipo de ocorrência era comum às hidrelétricas instaladas no interior do Brasil.

A partir da década de 1960, os impactos da desapropriação por grandes projetos passaram a ser discutidos em virtude da proposição da primeira política sobre reassentamento involuntário, pelo Banco Mundial (BIRD). Contudo, o fortalecimento desta questão deu-se na década de 1980, quando surgiram os primeiros movimentos sociais organizados na luta contra os deslocamentos forçados.

Assim como o Brasil viu surgir o Movimento dos Atingidos por Barragens (MAB), o município paranaense de São Mateus do Sul presenciou o surgimento do Movimento dos Atingidos pela PETROBRAS/SIX (MAP). Enquanto o propósito do MAB foi a discussão com os empreendedores de barragens sobre projetos de reassentamento, 0 do MAP era incluir a proposta de reassentamento no processo de negociação da desapropriação de terras das 
Comunidades Rio das Pedras e Dois Irmãos que seria realizada pela PETROBRAS/SIX a partir de 2005. (ASSUNÇÃO, 2002).

Contudo, esta proposta não foi considerada a melhor opção naquela situação por dois motivos principais: a inexistência de terras agricultáveis para serem adquiridas pela PETROBRAS-SIX; e, o interesse da maioria dos proprietários pela indenização monetária.

Segundo Sánchez (2008, p. 352) "o enfoque social parte do pressuposto de que a indenização monetária é uma compensação insuficiente para os impactos sociais [...]", pois estes extrapolam a questão da moradia e do trabalho atingindo as relações socioculturais criadas no âmbito da comunidade. Desta maneira, é imprescindível preservar a produção e reprodução cultural das famílias removidas do espaço no qual estavam enraizadas as tradições cultivadas por gerações.

O reassentamento procura recriar as condições de vida existentes antes da remoção involuntária, provendo o local com infra-estrutura e serviços com a mesma qualidade ou superior, para permitir a continuidade das relações econômicas, sociais e culturais já existentes entre as famílias. Quando se trata de famílias de agricultores, deve-se levar em consideração a fertilidade do solo e a disponibilidade de água, para que a produtividade alcançada seja semelhante às anteriores.

Para que se recrie as particularidades das relações desenvolvidas no interior da comunidade atingida é necessário garantir a participação da comunidade no processo de desapropriação, por meio de reuniões, entrevistas, audiências públicas, e outras. Conhecendo detalhadamente a comunidade será mais fácil propor um projeto de reassentamento adequado à realidade local.

\section{IMPACTOS DA MINERAÇÃO DO FOLHELHO PIROBETUMINOSO SOBRE A COMUNIDADE DOIS IRMÃOS}

Os efeitos dos impactos da mineração do folhelho pirobetuminoso sobre a Comunidade Dois Irmãos foram identificados através da observação direta intensiva e por meio da análise dos dados coletados com a aplicação de um 
questionário a 62 das 90 famílias que tiveram suas terras desapropriadas pela PETROBRAS-SIX, para a implantação da Mina Dois Irmãos, conforme explicitado na metodologia da pesquisa.

O perfil dos entrevistados é caracterizado por agricultores do sexo masculino (55\%) e feminino (45\%), com idade variável entre 20 e 80 anos de idade, predominando a faixa etária entre 41 e 60 anos (48\%).

A maioria dos entrevistados (83,5\%) possui baixo grau de escolaridade, tendo completado no máximo a 4⿳亠丷a série do Ensino Fundamental, enquanto 16\% possuem o Ensino Médio completo e apenas um dos entrevistados possui Ensino Superior, tratando-se de uma pedagoga.

Portanto, as características marcantes da maioria dos entrevistados quanto ao gênero, faixa etária e grau de instrução são, respectivamente: sexo masculino (55\%); idade entre 42 e 60 anos (48\%); e, escolaridade baixa (83\%).

Todos os entrevistados são membros de famílias da Comunidade Dois Irmãos, que tiveram suas terras desapropriadas pela PETROBRAS-SIX no ano de 2005, porém nem todos deixaram as propriedades neste mesmo ano. As primeiras famílias mudaram-se em fevereiro de 2006 e as últimas em julho de 2009.

Os entrevistados, que primeiro desocuparam suas propriedades, relataram que tiveram dificuldades na adaptação de seus cotidianos na nova área adquirida, porém atualmente já estão mais acostumados, considerando que a terra já está produzindo conforme esperavam. As famílias que desocuparam suas ex-propriedades em 2009 demonstram que ainda sentem dificuldades para se adaptar no novo local, mas reforçam acreditar que trata-se de uma situação momentânea, referindo-se às experiências positivas dos familiares e amigos que já passaram por processo semelhante em anos anteriores.

No processo de desapropriação, os agricultores tiveram a opção de escolher o tipo de negociação de suas terras, entre os quais poderia ser: indenização em dinheiro; permuta por outra área; carta de crédito; ou, outra forma de indicação própria que garantisse a satisfação pessoal e econômica de cada proprietário. Entre estes quatro tipos de negociação, apenas dois foram 
escolhidos pela comunidade. A maioria dos entrevistados (84\%) optou pela indenização em dinheiro, relatando que essa seria mais segura por permitir a livre escolha pela nova área de terra. Os $16 \%$ das famílias restantes, escolheram a permuta por outra área, justificando que preferiam receber outra área em condições semelhantes, destacando a preocupação com a supervalorização imobiliária que ocorreu após a desapropriação de terras da comunidade vizinha (Comunidade Rio das Pedras), no ano de 2002.

Embora, durante as primeiras reuniões realizadas pela PETROBRAS/SIX com a Comunidade Dois Irmãos, a maioria das famílias tivesse demonstrado forte interesse pelo processo de reassentamento, esta opção não foi indicada pelos entrevistados.

Essa repentina mudança de opinião deveu-se a dois principais fatos: (1) a indisponibilidade de áreas rurais na região, com solo de boa qualidade, para serem adquiridas pela PETROBRAS-SIX, para a realização desta modalidade de negociação; e, (2) o interesse de um pequeno grupo de agricultores pela indenização em dinheiro, que induziu a maioria a optar pela mesma forma de negociação de suas terras.

Durante a aplicação do questionário, os moradores relataram com freqüência suas expectativas e angústias em relação à desapropriação, pela qual passaram. Muitos demonstram insatisfação com o processo, embora tenham tido a oportunidade de participar da escolha da negociação de suas propriedades com a PETROBRAS/SIX. A maioria dos entrevistados (65\%) considera que as negociações da desapropriação foram injustas, enquanto $35 \%$ das famílias, revelou satisfação com o processo do início ao fim, informando que as negociações foram conduzidas de maneira pacífica e justa.

Sendo assim, fica evidente que o processo em si não trouxe satisfação para todos os desapropriados. A principal insatisfação está relacionada à obrigatoriedade de vender a propriedade, sem opção de negociação do valor a ser recebido, como se faz em um negócio qualquer.

A indenização monetária nem sempre traz benefícios às famílias desapropriadas de suas terras. Algumas famílias acabam empregando parte do capital recebido na aquisição no consumo de bens que não tinham acesso, 
deixando em segundo plano a aquisição da nova propriedade. Por vezes, a especulação imobiliária estimula a supervalorização das propriedades vizinhas àquelas desapropriadas, dificultando a aquisição de propriedade com condições semelhantes. É válido lembrar que, tornado público o processo de indenização em dinheiro, as famílias desapropriadas correm risco de se tornarem vítimas de estelionato e roubo. Diante disto, constata-se que as indenizações nem sempre reduzem os impactos sofridos pelas pessoas, sendo necessário repensar este tipo de negociação das terras.

Porém, as indenizações foram definidas a partir de pesquisa de mercado realizada pela empresa, a qual incluía a definição dos valores pagos pelas terras e benfeitorias existentes. Mesmo após a desapropriação, muitas famílias permaneceram nas propriedades, até julho de 2009, em comum acordo com a PETROBRAS/SIX.

As novas propriedades adquiridas distanciam-se das antigas num raio de até $12 \mathrm{~km}$, sendo que $65 \%$ fica a uma distância de até $4 \mathrm{~km}$ da área desapropriada, $27 \%$ de $4 \mathrm{~km}$ a $8 \mathrm{~km}$, e $8 \%$ de $8 \mathrm{~km}$ a $12 \mathrm{~km}$.

Além do distanciamento da antiga propriedade, as famílias da Comunidade Dois irmãos também tiveram seu trajeto diário alterado devido ao desvio da PR-364, que atravessava a área a ser minerada, utilizada como principal via de acesso à zona urbana de São Mateus do Sul, ou aos municípios próximos como, por exemplo, Mallet, Rebouças, Rio Azul e Irati.

Entre as insatisfações dos agricultores com a desapropriação está o fato da PR-364 ter sido desviada. O desvio desta estrada de rodagem alterou as distâncias percorridas por $70 \%$ das famílias entrevistadas. Dessas, 95\% tiveram seu trajeto aumentado e apenas $5 \%$ reduziu seu percurso diário. Alguns entrevistados demonstram preocupação com o ponto de coleta dos estudantes pelo transporte escolar, que se tornou mais longínquo.

Quando perguntado aos respondentes do questionário, quais eram os produtos finais produzidos a partir do folhelho pirobetuminoso, a maioria $(70 \%)$ afirmou desconhecer os produtos da PETROBRAS/SIX. Este fato coloca em evidência a importância da implementação de projetos que forneçam informações básicas sobre as atividades da empresa às comunidades vizinhas 
a sua área. Desta maneira, essa empresa poderá garantir o maior envolvimento da comunidade no processo de gestão ambiental, evitando conflitos desnecessários.

Embora a maioria desconheça os produtos finais da PETROBRAS/SIX, a maioria (76\%) acredita que as atividades da mineração do folhelho pirobetuminoso causam problemas ao meio ambiente, enquanto apenas 5\% respondeu não a este questionamento e 19\% não soube informar.

Quando indagado sobre o conceito de meio ambiente, a maioria (78\%) optou pela alternativa que incluía o ser humano como parte integrante deste meio. Esses dados demonstram que a maior parte das famílias desapropriadas, que tiveram a oportunidade de responder o questionário, tem consciência de que não são superiores à natureza, e que junto com ela formam o meio ambiente. Contudo, 3\% fazem parte do grupo de brasileiros que acreditam que meio ambiente é sinônimo de animais e florestas e os outros $19 \%$ excluíram os homens de seus conceitos, afirmando que o meio ambiente é formado por animais, florestas, rios e o ar que respiramos.

A aquisição do conceito correto de meio ambiente, poderá auxiliar na mudança de hábitos e atitudes tidos como corretos por parte desses agricultores, que no entanto contribuem, mesmo que involuntariamente, com o processo de degradação ambiental. Uma alternativa para implementar um projeto que vise a adoção de um nova postura ética em relação ao meio ambiente, que conduza a Comunidade Dois irmãos à sustentabilidade, é promover a sensibilização por meio da Educação Ambiental.

Para identificar o grau de influência direta da PETROBRAS/SIX na renda familiar dos desapropriados foi construída a seguinte pergunta: Alguém de sua família trabalha na Petrobras? Como se esperava pelo perfil dos entrevistados, 99\% respondeu não. Apenas 1\% confirmou que alguém da família trabalha na PETROBRAS/SIX, totalizando seis entrevistados, dos quais cinco são empregados de empresas terceirizadas e um é funcionário concursado.

Desta maneira, se explica o pequeno conhecimento da Comunidade sobre as atividades desenvolvidas pela Empresa, bem como sobre seus produtos. 
Como forma de minimizar os efeitos dos impactos ambientais da mineração sobre a Comunidade local, a PETROBRAS/SIX desenvolve projetos sociais como, por exemplo, cursos básicos que possam auxiliar na melhoria da qualidade de vida das pessoas envolvidas, bem como estimular 0 desenvolvimento de atividades que possam complementar a renda familiar. Para identificar a participação da Comunidade Dois Irmãos nesses projetos sociais, foi feita a seguinte pergunta aos entrevistados: Você ou alguém de sua família participa ou participou de algum projeto social desenvolvido pela Petrobras? As opções de respostas foram: sim participo; sim participei; e, não, nunca participei. As respostas revelaram que $50 \%$ dos entrevistados participa ou participou e $50 \%$ nunca participou.

Foi dada oportunidade ao respondente do questionário de mencionar em qual ou quais projetos sociais estava inserido ou havia participado. A maioria disse participar ou ter participado de cursos de curta duração, voltados ao desenvolvimento de competências e habilidades artesanais ou culinárias.

Embora a PETROBRAS/SIX esteja presente na Comunidade Dois Irmãos através dos projetos sociais implantados, a maior parte das famílias desapropriadas (56\%) afirmou não conhecer a empresa, ou seja, nunca fez uma visita interna, assim como $70 \%$ destes disseram desconhecer o que é produzido a partir do folhelho pirobetuminoso.

Esse fato revela a necessidade da empresa divulgar suas atividades, junto à comunidade, como forma de esclarecer prováveis dúvidas, que possam alterar o juízo de valor de cada indivíduo em relação os impactos ambientais gerados pela mineração do folhelho pirobetuminoso.

Uma das alternativas encontradas pela empresa para acompanhar 0 processo internos de mudanças na Comunidade Dois Irmãos foi a disponibilização de um serviço de assistência social às famílias que tiveram suas terras desapropriadas no ano de 2005. Uma Assistente Social foi encarregada de realizar visitas periódicas à Comunidade, antes e depois da desapropriação, na tentativa de identificar as angústias vivenciadas no cotidiano familiar. Porém, nem todas as famílias foram contempladas com este trabalho, conforme constatado com a aplicação da seguinte pergunta: A 
Petrobras fez algum tipo de trabalho de assistência social antes da desapropriação, como por exemplo: visitas e conversas, explicando porquê seriam desapropriados? Dos respondentes, $65 \%$ afirmou nunca ter recebido qualquer tipo de serviço como este, enquanto $35 \%$ optou pela alternativa "sim", confirmando que recebeu assistência social em período variado entre um e doze meses antecedentes à desapropriação.

Contudo, ao questioná-los sobre a assistência social prestada pela empresa após a desapropriação de terras, $72 \%$ das famílias afirmou ter recebido ou ainda receber este tipo de serviço, enquanto $28 \%$ disse nunca ter recebido. De maneira generalizada, os entrevistados se referem ao serviço recebido como sendo muito bom, pelo fato de terem um meio de comunicação com a empresa, representado pela assistente social.

Para averiguar se as famílias desapropriadas de suas terras haviam recebido algum tipo de orientação durante o processo de aquisição de novas propriedades, foi aplicada a seguinte questão: A Petrobras orientou você durante a compra da nova propriedade? A maioria (78\%) respondeu não, enquanto o sim foi a resposta de $22 \%$ dos entrevistados. Tanto no primeiro grupo quanto no segundo, os entrevistados demonstraram que foram feitas boas e más negociações, adquirindo mais ou menos terras, de melhor ou pior qualidade.

Para averiguar os benefícios e os prejuízos que a desapropriação de terras trouxe às famílias de agricultores que tiveram que se deslocar involuntariamente foi elaborada e aplicada a seguinte pergunta: Você considera que a desapropriação de suas terras para a exploração do xisto trouxe mais benefícios ou prejuízos para sua família? Dos entrevistados, $58 \%$ respondeu que a desapropriação de terras lhes trouxe prejuízos, entre os quais os mais citados foram a necessidade de reiniciar os cultivos que já se desenvolviam há mais de uma década, a perda da primeira safra da erva-mate, o que na nova propriedade levaria mais de 3 anos para ser retomada, e o distanciamento dos antigos vizinhos e parentes consangüíneos. Os $42 \%$ que demonstraram ter se beneficiado com a desapropriação, destacaram como melhor benefício a aquisição de áreas de terras maiores do que as que possuíam, registrando 
que o valor da indenização foi muito boa para eles.

Como forma de investigar os prejuízos sofridos pela comunidade em relação à qualidade das terras adquiridas após a desapropriação, conforme relatos dos agricultores durante as primeiras visitas realizadas pela pesquisadora na Comunidade Dois Irmãos, foi elaborada e aplicada a seguinte pergunta: A qualidade da terra para o plantio da propriedade adquirida depois da desapropriação é melhor, pior ou igual se comparada com a terra que sua família possuía?

Durante as visitas, muitos agricultores demonstravam insatisfação com a qualidade das novas terras para o plantio, porém, não havia uma quantificação precisa sobre a opinião formal da comunidade desapropriada, pois tratava-se de casos isolados. Contudo, com a aplicação do questionário, foi constatado que a maioria dos agricultores (58\%) adquiriu terras de melhor ou igual qualidade àquelas que possuía. No entanto, $42 \%$ revelou que as terras cultivadas atualmente não apresentam a mesma qualidade daquelas indenizadas pela empresa, pelo contrário, são piores.

Embora $42 \%$ dos entrevistados tenha dito ter adquirido terras de pior qualidade, não houve grande variação no tipo de produtos cultivados. As perguntas referentes aos tipos de produtos cultivados antes e depois da desapropriação, revelaram que os agricultores continuam produzindo o feijão e o milho em escala comercial, e dedicando-se ao cultivo ou extrativismo da erva-mate. A diferença constatada está no caso da erva-mate, que na antiga propriedade já estava em pronta para ser colhida, enquanto na propriedade nova não está, pois sendo uma cultura permanente, tem um período superior a três anos para iniciar a produção. Aquelas famílias que deixaram suas propriedades no ano de 2009 ainda estão aguardando os resultados do plantio das mudas de erva-mate.

Outra questão abordada foi a saúde, sendo questionado sobre o surgimento ou não de doenças diagnosticadas em decorrência do processo de desapropriação de terras. A questão que tratou deste tema, foi redigida da seguinte maneira: Alguma pessoa de sua família teve problema de saúde, diagnosticado por médicos, por causa da desapropriação? 
A elaboração dessa pergunta teve a intenção de verificar a realidade desta problemática, apontada pelos moradores da Comunidade Dois Irmãos, que relataram ter passado por estresse e depressão durante as negociações de suas terras com a PETROBRAS/SIX. Nesta etapa, anterior à aplicação do questionário, foram ditas algumas frases marcantes pelas pessoas que estavam sendo desapropriadas de suas terras como, por exemplo, "Não dava vontade nem de comer, sabendo que a gente tinha que deixar tudo pra trás.", "A gente sentia uma tristeza tão grande, porque sabia que não tinha o que fazer, tinha que vender as terras pra Petrobras. Contudo, não foi a maioria das pessoas que relatou o caso de algum ente familiar ter contraido alguma doença decorrente da desapropriação. Apenas $35 \%$ dos entrevistados afirmou que uma ou mais pessoas de sua família tiveram problemas de depressão ou estresse, contudo não foi possível verificar algum tipo de laudo médico, pois os mesmos não foram apresentados pelos moradores. Não se trata de colocar em dúvida as palavras dos agricultores que se apresentam como pessoas possuidoras de valores éticos e morais, porém a validação deste quantitativo sem a verificação de atestados médicos torna-se difícil, abrindo-se assim uma lacuna nesta questão, que poderá servir de alvo de investigação científica de futuros pesquisadores interessados no tema.

Considerando que os agricultores deixaram suas terras sobre as quais já tinham amplo conhecimento, fato que favorecia a escolha dos produtos a serem cultivados, bem como era possível estimar a produção final, e instalaram-se em áreas com características diferentes, foi necessário investigar se a empresa prestou algum tipo de assistência técnica, com o objetivo de auxiliar os agricultores na retomada de suas atividades econômicas, como havia feito no processo de desapropriação dos moradores da Comunidade Rio das Pedras. Como meio de identificar a atuação da empresa foi feito o seguinte questionamento: Depois que a Petrobras desapropriou suas terras ela prestou algum tipo de assistência técnica para auxiliar na retomada das atividades agrícolas ou pecuárias? Diante dessa pergunta os agricultores, em sua maioria (92\%) respondeu não, ou seja, apenas $8 \%$ afirmou que a empresa prestou auxílio, orientando por meio de cursos e visitas de técnicos agrícolas nas 
propriedades.

Para finalizar, foram aplicadas duas questões que se distinguiram das demais por apresentarem a múltipla escolha, permitindo a seleção de mais de uma resposta. A referente aos impactos ambientais desencadeados pela mineração do folhelho pirobetuminoso, foi apresentada aos respondentes da seguinte maneira: Entre os fatos listados abaixo, quais você considera que mais afetam você e sua família? Com esta pergunta teve-se o objetivo de verificar quais foram os impactos que mais alteraram as condições de vida da comunidade. As respostas foram variadas, sendo que $32 \%$ apontou a desapropriação como o fato que mais causou prejuízos, seguido das vibrações (tremores) que fazem tremer ou rachar a casa (30\%), barulhos e ruídos dos caminhões da PETROBRAS-SIX (15\%), barulho das explosões da mineração (13\%) e secagem dos poços d'água de sua propriedade (10\%).

Considerando que a desapropriação de terras é o impacto que mais afeta a comunidade Dois Irmãos, foi questionado sobre as atividades que foram prejudicadas com a desapropriação, tendo a seguinte redação: Quais atividades praticadas por você e sua família foram prejudicadas pela desapropriação de suas terras pela Petrobras?

Entre as opções de respostas, aquela definida como "outras" teve o maior número de indicações $(31 \%)$, sendo mencionada, principalmente o rompimento das relações sociais com vizinhos, amigos e parentes mantidas por décadas, devido ao distanciamento das propriedades, provocado pelo deslocamento involuntário das famílias. Em seguida, apontaram com a mesma porcetagem de indicação (25\%) a ajuda dos vizinhos no plantio ou colheita, como era feito nas propriedades antigas, e o uso de equipamentos e máquinas agrícolas compradas em sociedade por várias famílias, que passaram a morar distantes umas das outras. A alternativa menos apontada (19\%) foi a participação em missas, festas, reuniões, e outras.

Diante da aplicação do questionário foi possível obter a real situação da Comunidade Dois Irmãos frente aos efeitos dos impactos ambientais.

Constatou-se que a desapropriação interferiu significativamente no modo de vida das 90 famílias envolvidas neste processo. Muitas tiveram dificuldade 
em adquirir novas propriedades em condições semelhantes àquelas que possuíam, no entanto a maioria ficou satisfeita com a qualidade das terras que adquiriram.

Considerando que já se passaram cinco anos da finalização do processo formal de desapropriação, pode-se perceber e aceitar que o impacto ambiental não pode ser considerado apenas o resultado de uma ação que se finaliza, mas deve ser considerado um grande processo que se redireciona no espaço e no tempo a partir da eficiência das medidas mitigadoras aplicadas.

\section{CONSIDERAÇÕES FINAIS}

Entre os principais impactos desencadeados durante a fase de implantação da Mina Dois Irmãos a desapropriação de terras, apresenta-se como aquele que mais interferência provoca no meio antrópico, sendo merecedor de atenção da PETROBRAS/SIX, para evitar conflitos sócioambientais, pois as famílias desapropriadas revelam que ainda sentem os prejuízos financeiros e emocionais causados por esse processo.

Entre os prejuízos apontados pelos entrevistados (58\%) está a necessidade de reiniciar os cultivos que já se desenvolviam há mais de uma década, a perda da primeira safra da erva-mate - que na nova propriedade levaria mais de 3 anos para ser retomada - e o distanciamento dos antigos vizinhos e parentes consangüíneos. Por outro lado, $42 \%$ que demonstraram ter se beneficiado com a desapropriação, destacaram como maior benefício a aquisição de áreas de terras maiores do que as que possuíam, registrando que o valor da indenização satisfatório. Portanto, embora a maioria sinta-se prejudicada, a diferença entre as duas opiniões (prejuízo ou benefício) não há grande diferença. O projeto de reassentamento idealizado no início das negociações pela PETROBRAS/SIX com a Comunidade Dois Irmãos, não foi considerado importante pela maioria dos interessados, que acabaram optando pela indenização em dinheiro. Embora a maioria tenha feito essa opção, muitos demonstraram insatisfação com o processo.

Algumas famílias sentiram o impacto psicológico causado pela 
desapropriação, evidenciado através da manifestação de doenças como a depressão, conforme foi apontado por $65 \%$ dos entrevistados. Outros relataram dificuldade de adaptação na nova propriedade e a dificuldade de recomeçar o plantio das culturas que possuíam nas áreas desapropriadas.

Com a desapropriação, o rompimento das relações sociais cotidianas foram parcialmente prejudicadas, necessitando de um intensivo trabalho de assistência social. A PETROBRAS-SIX disponibiliza uma assistente social para acompanhar a adaptação das famílias nas novas propriedade, fato que tem contribuído para minimizar esse impacto. Contudo, algumas famílias revelaram que não são contempladas com este serviço, sendo necessário ampliar o atendimento à comunidade.

Diante dessas constatações fica evidente a necessidade de maior envolvimento e comprometimento da comunidade com a empresa como forma de serem evitadas pressões desnecessárias exercidas por grupos sociais contrários à mineração. Destaca-se também a importância da reflexão por parte da Empresa sobre as formas de indenização propostas pela desapropriação de terras, sendo indicada a possibilidade de reassentamento das famílias diretamente afetadas pelo deslocamento involuntário.

\section{REFERÊNCIAS}

ASSUNÇÃO, H. K. Parque industrial do Xisto: estratégia de desenvolvimento local para São Mateus do Sul. Florianópolis, 2002. $139 f$. Dissertação. (Mestrado em Geografia) - Setor de Ciências Exatas e Naturais, Universidade Federal de Santa Catarina.

BANDEIRA DE MELLO, C. A. Curso de Direito Administrativo. 5.ed. São Paulo: Malheiros, 1997.

BRASIL. Constituição da República Federativa do Brasil. Brasília: Senado Federal, 2004.

CONAMA. RESOLUÇÃO CONAMA 001/86. Disponível em: <http://www.mma.gov.br/port/conama/res/res86/res0186.html>. Acesso em 20 jun. 2008.

DECRETO de 24 de agosto de 2000. Disponível em: < http://www.jusbrasil.com.br/busca?q=DESAPROPRIAÇÃO+PELA+PETROBRA S\&S=legislacao $>$ Acesso em: 10 jun. 2009. 
DI PIETRO, M. S. Z. Direito Administrativo. 19. Ed. São Paulo: Atlas, 2006.

MEIRELLES, H. L. Direito Administrativo Brasileiro. 5. ed. São Paulo: Malheiros, 1995.

MINEROPAR. Petróleo e Xisto pirobetuminoso. Disponível em: http://www.mineropar.pr.gov.br/modules/conteudo/conteudo.php?conteudo=602 010> Acesso em: 13 jun 2010.

PETROBRAS. Estudo de Impacto Ambiental da Mina Dois Irmãos. São Mateus do Sul: Petrobras, 2006.

REVISTA PETROBRAS. Uma pedra também preciosa. Rio de Janeiro: Editada pelo Serviço de Relações Institucionais (SERINST/DIRINF/SERIMP). Edição especial. [199-]. $15 \mathrm{p}$.

SÁNCHEZ, L.E. Avaliação de Impacto Ambiental: conceitos e métodos. São Paulo: Oficina de Textos, 2008. 